\title{
SISTEM PENGENALAN WAJAH DENGAN METODE EUCLIDEAN DISTANCE
}

\author{
Dedy Harto ${ }^{1}$, Muhammad Zaki Rahmani² \\ ${ }^{1,2}$ Program Studi Teknik Elektro, Universitas Borneo Tarakan, Tarakan, Kalimantan Utara, Indonesia \\ Email: ${ }^{1}$ dedy@borneo.ac.id, ${ }^{2}$ muh.zaki.rahmani@gmail.com
}

\begin{abstract}
Biometrics is computer technology for the recognition of oneself through certain body parts. The use of pupil eyes as a feature of a person is the result of extracting facial features using geometry features, measurement of distance between eyes is still manually so that it requires a system that directly displays the results of measurements to obtain PD values that can be directly used to identify someone. This study designed a face recognition system through the MATLAB GUI to simplify the process of image capture and processing. The image is taken using a smartphone that is connected directly to a portable computer wirelessly through the Internet Protocol Camera system. The number of image samples used amounted to 50 samples for the database and 100 samples for the test data consisting of 10 people with the composition of 5 men and 5 women. Image processing uses the Viola-Jones method to detect faces in the second area of the eye and uses the Euclidean distance method to find the pupillary distance value which is then followed by image grouping based on that range of values and ends with facial recognition system testing. The test uses 100 samples of image data consisting of 5 men and 5 women with each of the 10 image data. Based on the results of these tests, the accuracy of face recognition system is obtained by $73 \%$ and the accuracy value based on gender for men is $78 \%$ and women are $68 \%$. With face matching speed of about 2-3 seconds..
\end{abstract}

Keywords-PD (Pupillary Distance), geometri, GUI MATLAB, viola-jones, euclidean distance.

Intisari-Biometrik merupakan teknologi komputer untuk pengenalan diri seseorang melalui bagian tubuh tertentu. Penggunaan pupil mata sebagai ciri seseorang merupakan hasil dari pada ekstrak ciri wajah dengan menggunakan fitur geometri, pengukuran jarak antar mata masih dengan cara manual sehingga membutuhkan sebuah sistem yang secara langsung menampilkan hasil dari pada pengukuran untuk memperoleh nilai PD yang dapat langsung digunakan untuk mengenali seseorang. Penelitian ini merancang sistem pengenalan wajah melalui GUI MATLAB untuk mempermudah proses pengambilan citra dan pengolahannya. Pengambilan citranya menggunakan ponsel pintar yang terhubung langsung dengan komputer jinjing secara nirkable melalui sistem Internet Protocol Camera. Jumlah sampel citra yang digunakan berjumlah 50 sampel untuk basis data dan 100 sample untuk data uji yang terdiri dari 10 orang dengan komposisi 5 laki-laki dan 5 perempuan. Proses pengolahan citra menggunakan metode viola-jones untuk mendeteksi wajah pada area kedua mata dan menggunakan metode euclidean distance untuk mencari nilai pupillary distance yang kemudian dilanjutkan pengelompokan citra berdasarkan rentang nilai tersebut dan diakhiri dengan pengujian sistem pengenalan wajah. Pengujian menggunakan 100 sampel data citra yang terdiri dari 5 laki-laki dan 5 perempuan dengan masing-masing 10 data citra. Berdasarkan hasil pengujian tersebut maka didapatkan nilai akurasi sistem pengenalan wajah sebesar 73\% dan nilai akurasi berdasarkan jenis kelamin untuk laki-laki $78 \%$ dan perempuan $68 \%$. Dengan kecepatan pencocokan wajah sekitar 2-3 detik.

Kata Kunci-PD (Pupillary Distance), geometri, GUI MATLAB, viola-jones, euclidean distance..

\section{PENDahuluan}

Perkembangan teknologi dunia digital mengalami kemajuan yang sangat pesat mendorong terciptanya sistem pengenalan wajah melalui ciri-ciri pada wajah. Mata merupakan salah satu indra manusia yang terdapat pada wajah seseorang selain mulut dan hidung. Sepasang mata dapat menjadi ciri khusus, terutama pada bagian retina dan pupil. Terdapat jarak antara pupil mata kanan dan kiri yang dikenal sebagai PD (Pupillary Distance) atau IPD (Interpupillary Distance) atau jarak antar pupil yang dapat digunakan sebagai pengenalan biometrik pada seseorang.

Sistem biometrik merupakan teknologi pengenalan diri yang menggunakan bagian tubuh atau perilaku manusia pada umumnya. Sepertihalnya sidik jari, tanda tangan, DNA, telinga, wajah, infrared, gaya berjalan, geometri tangan, gaya penekanan tombol, bau, telapak tangan, retina, suara, gigi, dan bibir. Masing-masing merupakan karakteristik dari pada sistem pengenalan diri. Sistem ini ada untuk mengenali identitas seseorang secara otomatis menggunakan teknologi komputer, yang bertujuan untuk meningkatkan keamanan sistem dan untuk mengenali target secara cepat dan tepat [1].

Secara umum sistem pengenalan citra wajah dibagi menjadi dua jenis, yaitu sistem feature based dan sistem image based. Pada sistem pertama digunakan fitur yang diekstraksi dari komponen citra wajah (mata, hidung, mulut, dan lain-lain) yang kemudian hubungan antara ciriciri tersebut dimodelkan secara geometris. Sedangkan sistem kedua menggunakan informasi mentah dari piksel citra yang kemudian direpresentasikan dalam metode tertentu, misalnya Principal Component Analysis (PCA), transformasi wavelt, GLCM yang kemudian digunakan untuk klasifikasi identitas citra [2].

Pupillary distance (PD) atau interpupillary distance (IPD) atau jarak antar pupil merupakan pengukuran jarak antar titik tengah pupil pada sepasang mata pada manusia. Jarak antara pupil mata setiap orang berkisar $58 \mathrm{~mm}$ sampai $70 \mathrm{~mm}$. Nilai PD pada setiap orang bervariasi berdasarkan umur, jenis kelamin, dan ras keturunan. 
Dalam penelitian dengan jumlah sampel 3976 orang, berdasarkan distribusi data pengukurannya terdapat nilai ketidakseragaman berdasarkan ras keturunan mencapai $99 \%$ dan berdasarkan usia mencapai $95 \%$. Nilai rata-rata PD pada laki-laki dan perempuan memiliki selisih perbedaan, nilai tersebut juga mengalami perubahan seiring dengan pertambahan umur [3].

Penggunaan pupil mata sebagai ciri seseorang merupakan hasil dari pada ekstrak ciri wajah. Terdapat ekstrasi ciri wajah dengan menggunakan fitur geometri, berupa jarak antara pupil mata. Secara umum geometri adalah ilmu ukur yang berhubungan dengan bentuk, ukuran, dan posisi hingga sifat ruang, hasilnya memunculkan ilmu pengetahuan praktis tentang panjang, luas, dan volume. Dipelopori oleh Euclid (abad ke-3 SM) dengan nama geometri euclid. Ilmu ukur ini menjadi standar selama berabad-abad dan kemudian disempurnakan hingga sekarang dan menjadi sebuah metode perhitungan yang dikenal sebagai metode euclidean distance.

Saat ini telah ada pengembangan sistem pengenalan wajah, seperti pengenalan wajah menggunakan alihragam wavelet haar dan jarak euclidean dengan tingkat keberhasilan pengenalan mencapai 96\%[4]. Penerapan euclidean distance pada eigenface untuk monitoring ruangan secara realtime berbasis webcam dengan pencocokan wajah dengan tingkat pengenalan hingga $88 \%$ [5]. Pengenalan wajah dengan menggunakan metode centroid dan geometric mean dengan nilai akurasi mencapai 96\% [6]. Sedangkan pada perbandingan metode viola-jones dengan metode roberts cross pada sistem pengenalan wajah, dengan metode viola-jones lebih unggul dalam hal kecepatan pendeteksian wajah dengan nilai 95\% [7], metode nilai jarak guna kesamaan atau kemiripan ciri suatu citra yang menggunakan perbandingan antar metode pengukuran, dengan tingkat keakuratan metode euclidean distance lebih baik dari manhattan dan mahalanobis [8].

Berdasarkan teori dan pengembangan mengenai sistem pengenalan wajah sebelumnya maka pada tugas akhir ini akan dirancang sebuah sistem pengenalan wajah dengan menggunakan metode euclidean distance dan metode viola-jones.

\section{LANDASAN TEORI}

A. Mata

Mata adalah organ penglihatan pada manusia. Mata mendeteksi cahaya dan mengubahnya menjadi impuls elektrokimia pada sel saraf.

\section{B. Citra}

Citra atau gambar dapat didefinisikan sebagai sebuah fungsi dua dimensi, $f(x, y)$, di mana $x$ dan $y$ adalah koordinat bidang datar, dan harga fungsi $f$ di setiap padang koordinat $(\mathrm{x}, \mathrm{y})$ Jika $\mathrm{x}, \mathrm{y}$ dan $\mathrm{f}$ semuanya berhingga (finite), dan nilainya diskrit, maka gambarnya disebut citra digital (gambar digital). Sebuah citra digital terdiri dari sejumlah elemen yang berhingga, di mana masingmasing mempunyai lokasi dan nilai tertentu. Elemenelemen ini disebut sebagai picture element, image element, pels atau pixel.[9]

\section{Pengolahan Citra Digital}

Pengolahan citra digital adalah sebuah disiplin ilmu yang mempelajari hal-hal yang berkaitan dengan perbaikan kualitas gambar (peningkatan kontras, transformasi wama, restorasi citra), transformasi gambar (rotasi, translasi, skala, transformasi geometrik), melakukan pemilihan citra ciri (feature images) yang optimal untuk tujuan analisis, melakukan proses penarikan informasi atau deskripsi objek atau pengenalan objek yang terkandung pada citra, melakukan kompresi atau reduksi data untuk tujuan penyimpanan data, transmisi data, dan waktu proses data. Input dari pengolahan citra adalah citra, sedangkan output-nya adalah citra hasil pengolahan[10].

\section{Jenis-jenis Citra Digital}

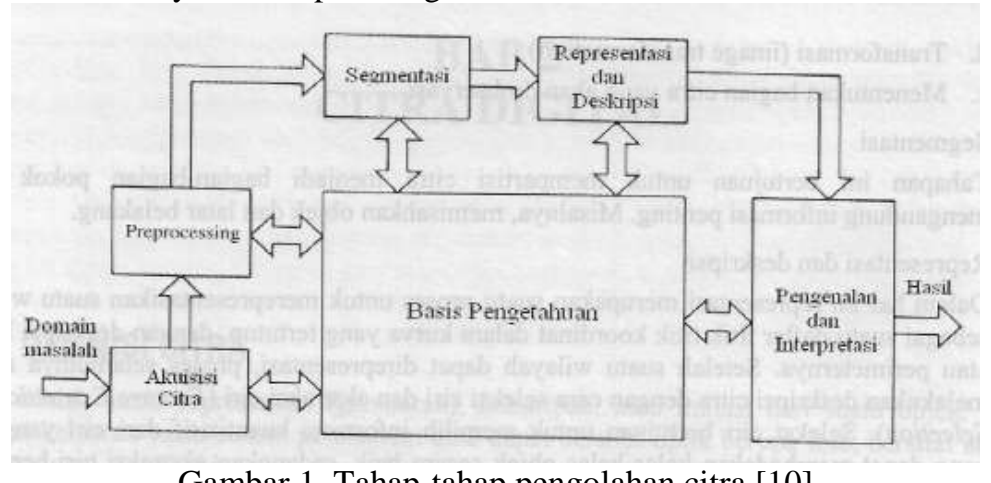

Gambar 1. Tahap-tahap pengolahan citra [10]

Langkah-langkah penting dalam pengolahan citra secara umum dijabarkan menjadi beberapa langkah; Akuisisi Citra, Preprocessing, Segmentasi, Representasi dan Deskripsi, Pengenalan dan Interpetasi, dan Basis Pengetahuan.

\section{E. Jenis-Jenis Citra Digital}

Citra digital terdiri dari, citra biner, citra grayscale dan citra warna.

\section{F. Elemen-elemen Citra Digital}

Elemen-elemen Citra Digital terdiri dari, Kecerahan (brightness), Kontras (contrast), Warna (color), Bentuk (shape), dan Tekstur (texture)

\section{G. Operasi Pemotongan}

Operasi cropping adalah pengolahan citra dengan kegiatan memotong satu bagian dari citra. 


\section{H. Operasi Citra Biner}

Pengolahan Citra digital membutuhkan memori yang jauh lebih besar dibandingkan dengan pengolahan tesk pada komputer. Untuk menghemat kebutuhan memori, warna citra diubah ke tingkat grayscale terendah yang berarti citra hanya mengandung informasi hitam atau putih pada piksel-piksel penyusunnya, yang disebut juga dengan citra biner, sehingga operasi dapat tetap dijalankan walaupun memori yang tersedia relatif kecil.

\section{Geometri Pada Citra}

Sifat-sifat geometri dari objek bisa dipakai sebagai ciri objek tersebut di dalam citra, yang meliputi ukuran, lokasi, bentuk, orientasi (sudut kemiringan objek terhadap garis acuan yang digunakan), dan ciri lain yang berguna untuk mengenali objek dalam citra yang dianalisis. Untuk mengenali dan menentukan ciri-ciri tersebut, kita misalkan saja pada sebuah citra hanya terdapat satu objek sehingga algoritma untuk menghitung ciri-ciri tadi dapat langsung diterapkan dengan cara yang lebih sederhana.

\section{J. Pelabelan Komponen}

Pada Citra mengandung objek lebih dari satu maka ciri mendasar dari masung-masing objek dapat dihitung secara sendiri-sendiri melalui operasi pelabelan, yaitu dengan cara menemukan komponen terkoneksi dalam citra karena suatu komponen terkoneksi mewakili sebuah objek.

\section{K. Filter Ukuran}

Biasanya setelah citra grayscale diubah menjadi citra biner melalui proses binerisasi, pada citra masih terdapat noise akibat kesalahan dalam mengelompokan pikselpiksel ke dalam golongannya sehingga komponen terkoneksi dengan ukuran dibawah nilai tersebut dapat berkelakuan sebagai noise. Filter ukuran digunakan untuk menghapus noise jenis ini.

\section{Tresholding}

Metode ini menggunakan nilai ambang $\mathrm{T}$ pada citra sebagai patokan untuk memutuskan sebuah piksel diubah menjadi hitam atau putih.

\section{Viola-Jones}

Metode viola-jones merupakan salah satu metode pendeteksian objek yang cukup populer dan banyak digunakan untuk pengembangan metode lainnya, metode viola-jones dapat memberikan hasil dengan tingkat persentase keakuratan yang cukup tinggi dan dengan kecepatan pengenalan yang sangat tinggi hingga 15 frame per detik.

\section{N. Jarak Euclidean}

Metode Euclidean adalah suatu metode pencarian kedekatan nilai jarak dari 2 buah variabel, selain mudah metode ini juga tidak memakan waktu, dan proses yang cepat.

\section{Euclidean distance $(d)=$ $\sqrt{\left(x_{2}-x_{1}\right)^{2}+\left(y_{2}-y_{1}\right)^{2}}$}

\section{O. IP Webcam}

IP Webcam adalah sebuah aplikasi Android pada smartphone yang dapat mengonversi perangkat Android menjadi sebuah kamera internet atau Internet Protocol Camera,

\section{P. Matlab}

MATLAB (Matrix Laboratory) adalah sebuah program pengembangan untuk analisis dan komputasi numerik dan merupakan suatu bahasa pemrograman matematika lanjutan yang dibentuk dengan dasar pemikiran menggunakan sifat dan bentuk matriks. MATLAB telah berkembang menjadi sebuah environment pemrograman yang canggih yang berisi fungsi-fungsi built-in untuk melakukan tugas pengolahan sinyal, aljabar linier, dan kalkulasi matematis lainnya [11].

\section{Q. GUI Matlab}

GUI atau Graphical User Interface merupakan tampilan grafis yang memudahkan user berinteraksi dengan perintah teks. Dengan GUI, program menjadi lebih friendly, sehingga user mudah menjalankan suatu aplikasi program [12].

\section{METODE PENELITIAN}

\section{A. Perancangan Pengambilan Data}

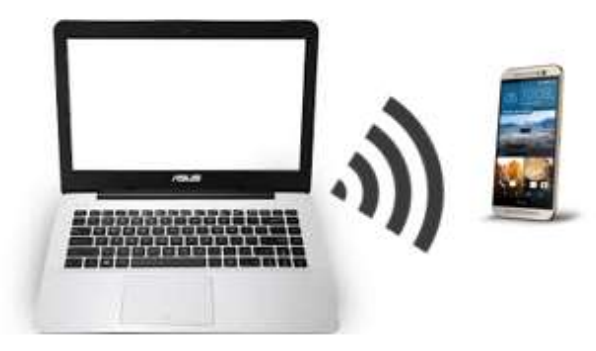

Gambar 2. Koneksi Laptop dan Smartphone 


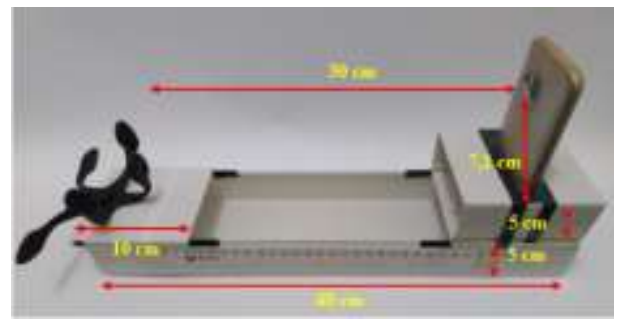

Gambar 3. Alat bantu peragaan pengambilan citra wajah

Pengambilan data citra dilakukan secara langsung, dengan jumlah data basis 50 citra dan data uji 100 citra.

\section{B. Perancangan Kerja Perangkat Lunak Sistem.}

Perancangan perangkat lunak sistem pengenalan wajah memiliki beberapa ketentuan agar sistem dapat berjalan dengan baik, ketentuan tersebut adalah sebagai berikut:

1. Input citra menggunakan kamera smartphone HTC one M9 dengan format file JPEG/JPG dengan resolusi 1920x1920 px.

2. Kamera smartphone terhubung secara wireless pada laptop dengan sistem Internet Protocol Camera.

3. Menggunakan metode viola-jones untuk mendeteksi area wajah khususnya pemotongan citra kedua mata.

4. Menggunakan metode euclidean distance untuk menghitung jarak antara PD.

5. Menggunakan nilai PD sebagai dasar dalam sistem pengenalan wajah.

6. Data basis yang tersimpan berisikan 5 citra wajah pada setiap 10 orang yang terdiri dari 5 laki-laki dan 5 perempuan.

7. Pengujian Sistem pengenalan wajah menggunakan 100 data citra dengan masing-masing 10 citra berdasarkan 10 orang (5 laki-laki \& 5 perempuan).

8. Jarak pengambilan citra wajah berjarak $30 \mathrm{~cm} \pm 0.5$.

9. Posisi wajah khususnya mata diatur dan dibatasi posisinya dengan hanya boleh menghadap kearah depan lurus ke kamera secara horisontal serta posisi kepala tegap lurus vertikal.

10. Ekspresi wajah normal dengan Keadaan mata diusahakan dalam posisi terbuka lebar (besar) tidak dengan keadaan mata sipit (kecil) atau menjulingkan mata secara sengaja serta dengan tidak menggunakan bantuan tangan dan alat bantu lainnya.

11. Sistem pengenalan wajah hanya dapat mengenali apabila menunjukkan wajah secara utuh tanpa tertutupi atau terhalangi oleh benda apapun terutama pada bagian wajah khususnya mata.

12. Pencahayaan pada lingkungan sekitar setidaknya harus terang (minimal harus ada sumber cahaya yang menuju ke wajah untuk ditangkap kamera).

Maka dengan ketentuan diatas dibuatlah sebuah sistem pengenalan wajah sebagai berikut:

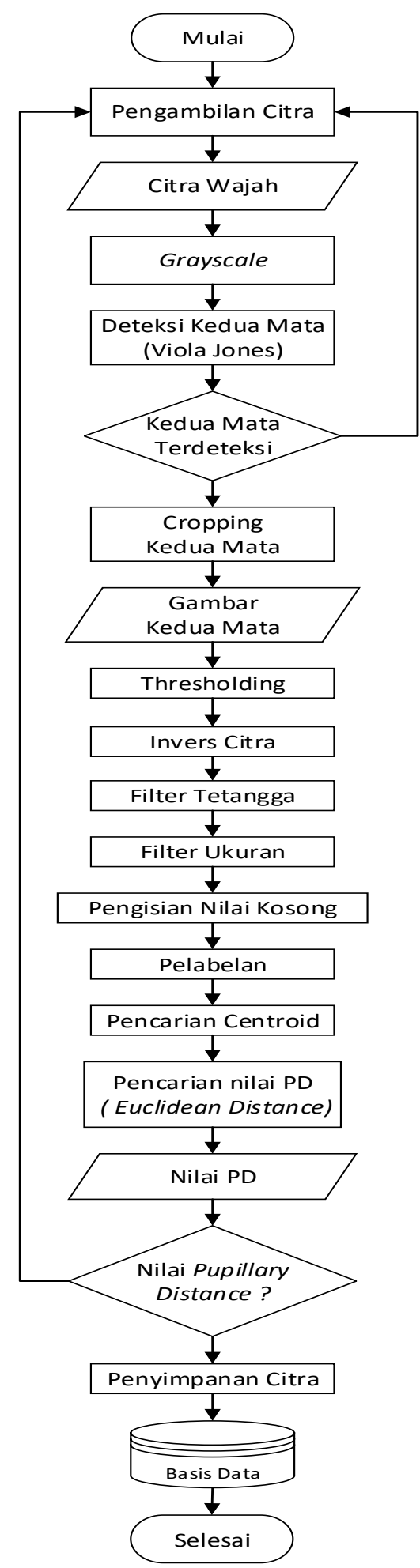

Gambar 4. Diagram alir perancangan kerja perangkat lunak sistem pengenalan wajah 


\section{Perancangan Pengujian Sistem}

Pengujian pada basis data dilakukan dengan mengunakan basis data itu sendiri, diketahui terdapat 50 sample citra pada basis data, untuk menghitung tingkat akurasi dari pada basis data maka dengan menggunakan persamaan dibawah.

$$
\text { Akurasi Basis (96) }=\frac{2 \text { Pengujian }- \text { Kosalahan }}{\sum \text { Pengujian }} \times 10036
$$

Pengujian sistem pengenalan wajah dilakukan untuk mengetahui tingkat akurasi sistem yang telah dibangun, diketahui terdapat 100 sample citra sebagai data uji, untuk menghitung tingkat akurasinya digunakanlah persaman sebagai berikut.

$$
\text { Akurasi Sistem(96) }=\frac{2 \text { Pengujian }- \text { Kesalahtan }}{\sum \text { Pengujian }} \times 10036
$$

Proses pengujian dapat dilihat melalui diagram alir sebagai berikut.

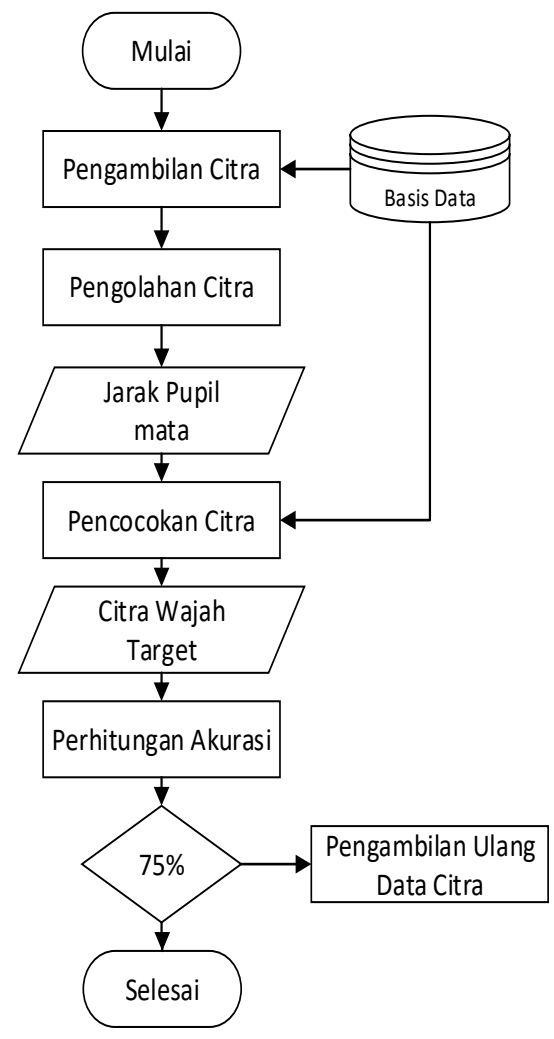

Gambar 5. Diagram alir perancangan pengujian Pengujian basis data

\section{Perancangan GUI Sistem}

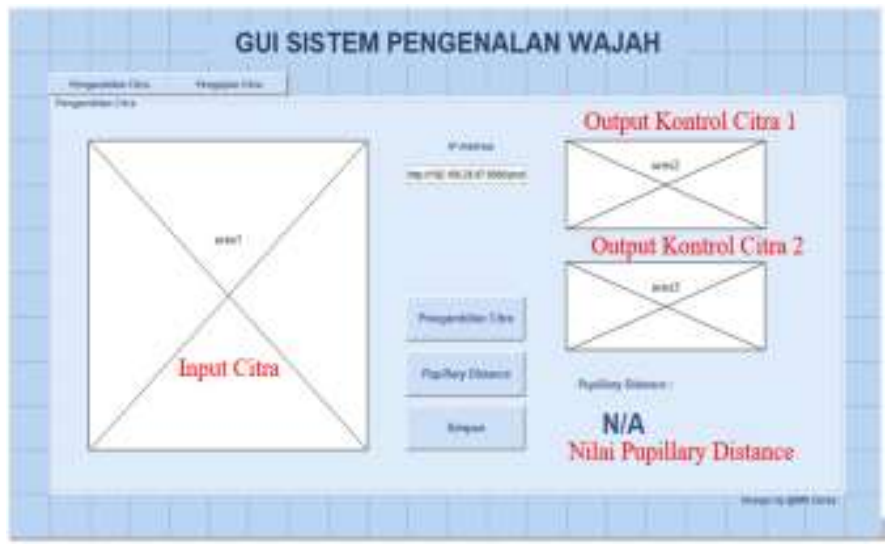

Gambar 6. Perancangan tampilan GUI pengambilan data

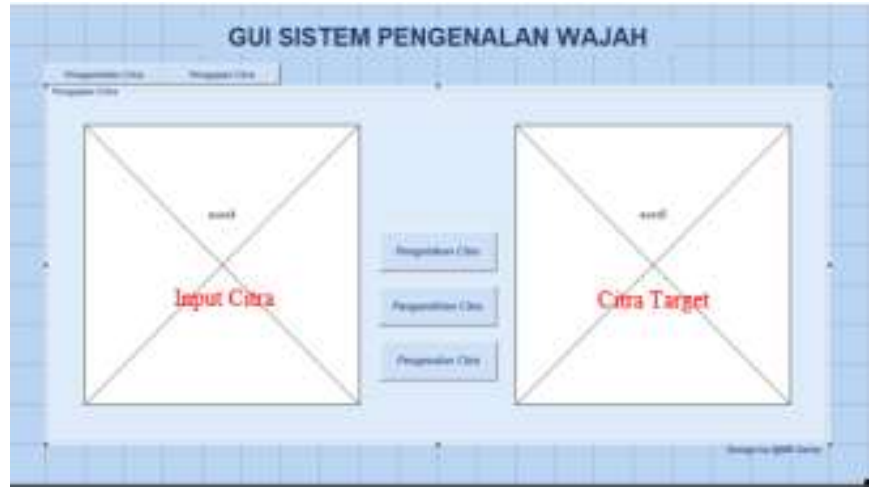

Gambar 7. Perancangan tampilan GUI pengujian data 


\section{HASIL DAN PEMBAHASAN}

A. Keterangan Proses Pengolahan Citra
Berikut ini merupakan hasil dari pada proses Pengolahan citra yang di dapat ditampilkan melalui GUI MATLAB yang telah di rancang.

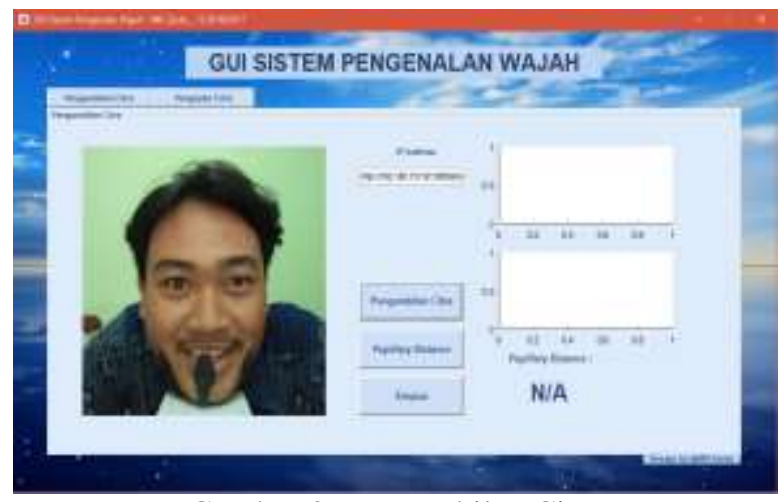

Gambar 8. Pengambilan Citra

Proses Pengambilan citra secara langsung melalui kamera smartphone yang telah dihubungkan secara wireless

\section{Proses Gayscale}

Pada gambar 9, adalah proses dari citra warna ke citra grayscale.
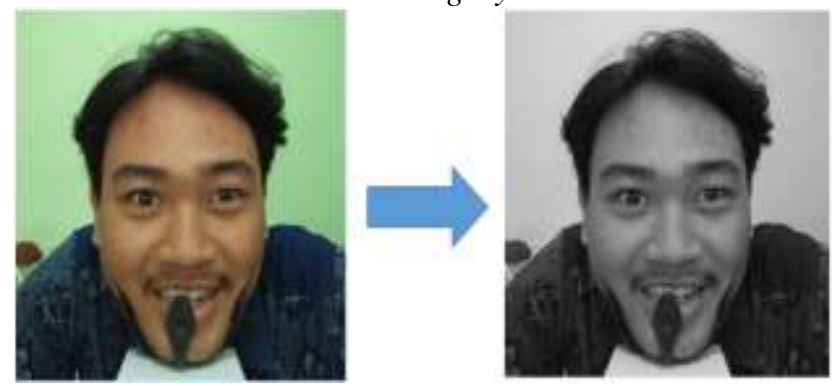

Gambar 9. Pengambilan Citra
2. Proses Viola-Jones \& Cropping

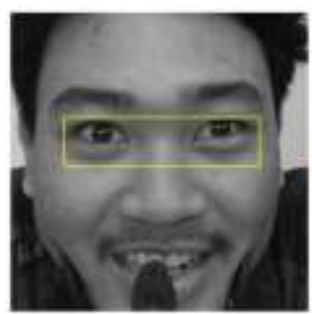

Gambar 10. Viola-Jones \& Cropping
Pada gambar 10 merupakan hasil dari proses ViolaJones dan melakukan cropping pada citra.

\section{Proses Tresholding}

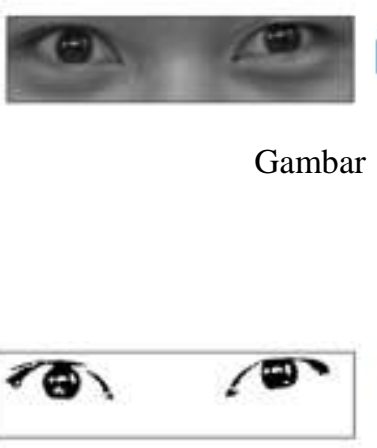

4. Proses Invers
Pada Gambar 11, merupakan proses dari thresholding untuk daerah mata.

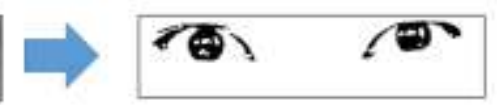

11. Tresholding

Pada gambar 12 merupakan hasil dari citra threshold ke citra yang sudah di invers.

Gambar 12. Invers 
5. Proses Filter Tetangga

\section{$\vec{E} \quad \vec{\theta}$}

Gambar 13. Filter Tetangga

6. Proses Filter Ukuran

7. Proses Pelabelan

8. Proses Pencarian Centroid

Gambar 14. Filter Ukuran

Gambar 15. Pelabelan
Pada gambar 13 merupakan hasil dari citra yang di invers ke bentuk proses filter tetangga.

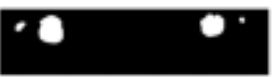

Pada gambar 14 merupakan proses dari hasil filter tetangga ke filter ukuran.

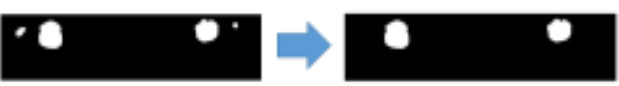

Pada gambar 15, merupakan hasil dari filter ukuran ke proses pelabelan.

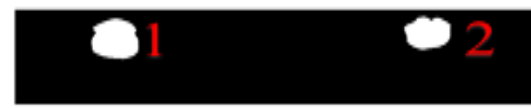

Pada gambar 16 merupakan hasil akhir dari proses pencarian centroid.

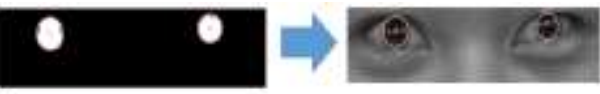

Gambar 16. Pencarian Centroid
Menghitung Nilai Pupillary Distance Setelah Mengetahui titik centroid pada pupil mata kanan dan kiri, maka selanjutnya adalah melakukan proses perhitungan jarak antar pupil mata melalui perhitungan sebagai berikut.

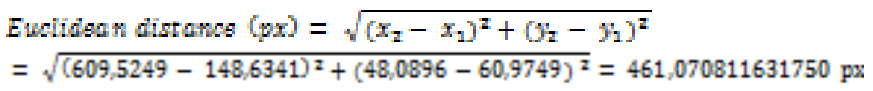

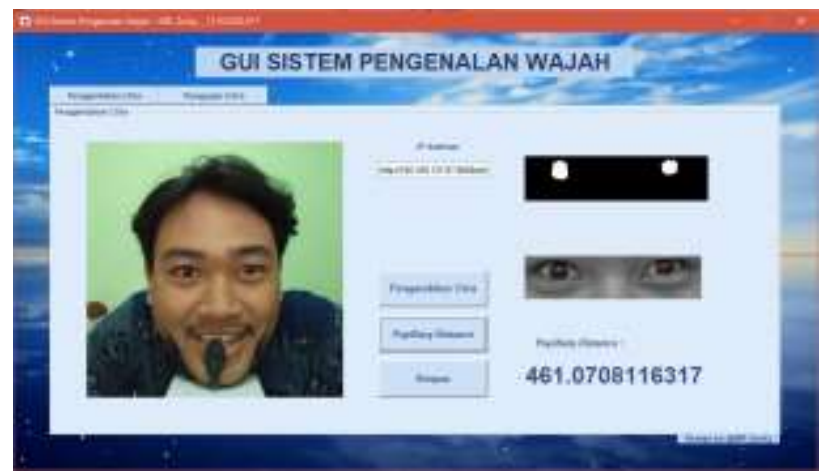

Gambar 17. Tampilan GUI

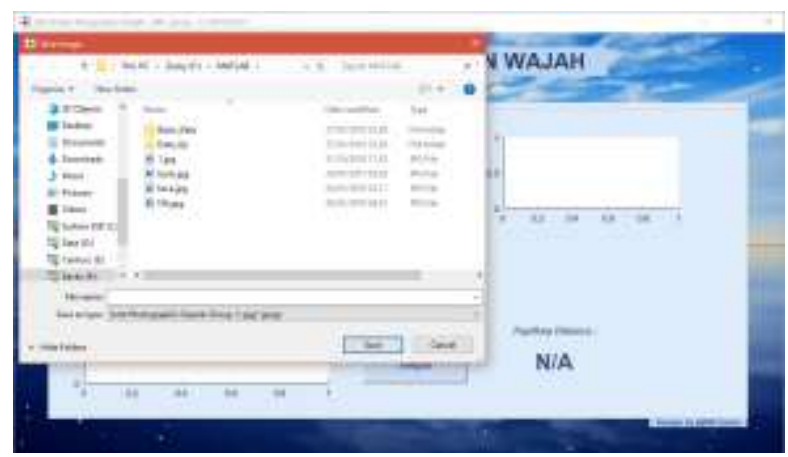

Gambar 18. Penyimpanan Citra 
9. Hasil Pengolahan Citra

Berdasarkan Proses pengolahan citra pada proses sebelumnya maka dengan melakukan pemrosessan pada 50 sample citra basis data dengan hasil sbb.

Table I

Hasil Pengolahan Citra

\begin{tabular}{|c|c|c|c|c|c|}
\hline No. & $\begin{array}{l}\text { Data } \\
\text { Citra }\end{array}$ & $\begin{array}{l}\text { Nilai PD } \\
\quad(\mathbf{p x})\end{array}$ & No. & $\begin{array}{l}\text { Data } \\
\text { Citra }\end{array}$ & $\begin{array}{c}\text { Nilai PD } \\
\quad(\mathbf{p x})\end{array}$ \\
\hline 1 & $\mathrm{~L}(1)$ & 458,0563 & 1 & $\mathrm{P}(1)$ & 419,6009 \\
\hline 2 & $\mathrm{~L}(1)$ & 460,1696 & 2 & $\mathrm{P}(1)$ & 422,9218 \\
\hline 3 & $\mathrm{~L}(1)$ & 461,1224 & 3 & $\mathrm{P}(1)$ & 418,0881 \\
\hline 4 & $\mathrm{~L}(1)$ & 461,0923 & 4 & $\mathrm{P}(1)$ & 420,3653 \\
\hline 5 & $\mathrm{~L}(1)$ & 463,3248 & 5 & $\mathrm{P}(1)$ & 418,1277 \\
\hline 6 & $\mathrm{~L}(2)$ & 451,1379 & 6 & $\mathrm{P}(2)$ & 448,1504 \\
\hline 7 & $\mathrm{~L}(2)$ & 453,5757 & 7 & $\mathrm{P}(2)$ & 447,5257 \\
\hline 8 & $\mathrm{~L}(2)$ & 451,9672 & 8 & $\mathrm{P}(2)$ & 445,8844 \\
\hline 9 & $\mathrm{~L}(2)$ & 451,6505 & 9 & $\mathrm{P}(2)$ & 446,3926 \\
\hline 10 & $\mathrm{~L}(2)$ & 453,8625 & 10 & $\mathrm{P}(2)$ & 450,9378 \\
\hline 11 & $\mathrm{~L}(3)$ & 500,8454 & 11 & $\mathrm{P}(3)$ & 412,6265 \\
\hline 12 & $\mathrm{~L}(3)$ & 500,8706 & 12 & $\mathrm{P}(3)$ & 408,3207 \\
\hline 13 & $\mathrm{~L}(3)$ & 502,0355 & 13 & $\mathrm{P}(3)$ & 409,7308 \\
\hline 14 & $\mathrm{~L}(3)$ & 505,8747 & 14 & $\mathrm{P}(3)$ & 409,7215 \\
\hline 15 & $\mathrm{~L}(3)$ & 503,0878 & 15 & $\mathrm{P}(3)$ & 412,4687 \\
\hline 16 & $\mathrm{~L}(4)$ & 469,5363 & 16 & $\mathrm{P}(4)$ & 435,6867 \\
\hline 17 & $\mathrm{~L}(4)$ & 470,0423 & 17 & $\mathrm{P}(4)$ & 433,3541 \\
\hline 18 & $\mathrm{~L}(4)$ & 469,1004 & 18 & $\mathrm{P}(4)$ & 433,4137 \\
\hline 19 & $\mathrm{~L}(4)$ & 470,7736 & 19 & $\mathrm{P}(4)$ & 430,1859 \\
\hline 20 & $\mathrm{~L}(4)$ & 465,9149 & 20 & $\mathrm{P}(4)$ & 433,5561 \\
\hline 21 & $\mathrm{~L}(5)$ & 470,9207 & 21 & $\mathrm{P}(5)$ & 416,3964 \\
\hline 22 & $\mathrm{~L}(5)$ & 475,2740 & 22 & $\mathrm{P}(5)$ & 412,9445 \\
\hline 23 & $\mathrm{~L}(5)$ & 474,9300 & 23 & $\mathrm{P}(5)$ & 414,5848 \\
\hline 24 & $\mathrm{~L}(5)$ & 475,6406 & 24 & $\mathrm{P}(5)$ & 417,4992 \\
\hline 25 & $\mathrm{~L}(5)$ & 473,0995 & 25 & $\mathrm{P}(5)$ & 416,4354 \\
\hline
\end{tabular}

Berdasarkan nilai diatas maka di dapatkanlah hasil pengolahan nilai untuk mencocokan wajah seseorang melalui range sebagai berikut.
Tabel II

Range Nilai PD (Px)

\begin{tabular}{|c|c|c|c|}
\hline \multirow{2}{*}{ No. } & \multirow{2}{*}{$\begin{array}{c}\text { Data } \\
\text { Citra }\end{array}$} & Range Nilai PD (Px) \\
\cline { 3 - 4 } & $\mathrm{L}(1)$ & 458,0563 & 463,3248 \\
\hline 1 & $\mathrm{~L}(2)$ & 451,1379 & 453,8625 \\
\hline 2 & & & \\
\hline & & 500,8454 & 505,8747 \\
\hline 3 & $\mathrm{~L}(3)$ & 46,9149 & 470,7736 \\
\hline 4 & $\mathrm{~L}(4)$ & 465,969 \\
\hline 5 & $\mathrm{~L}(5)$ & 470,9207 & 475,6406 \\
\hline 6 & $\mathrm{P}(1)$ & 418,0881 & 422,9218 \\
\hline 7 & $\mathrm{P}(2)$ & 445,8844 & 450,9378 \\
\hline 8 & $\mathrm{P}(3)$ & 430,1859 & 435,6867 \\
\hline 9 & $\mathrm{P}(4)$ & 430,1859 & 435,6867 \\
\hline 10 & $\mathrm{P}(5)$ & 412,9445 & 417,4992 \\
\hline
\end{tabular}

B. Proses Pelatihan Citra Basis

Tabel III

Hasil Pelatihan Citra Basis

\begin{tabular}{|c|c|c|c|c|c|}
\hline No. & $\begin{array}{c}\text { Data } \\
\text { Citra }\end{array}$ & Nilai PD & Target & Hasil & Keterangan \\
\hline 1 & $\mathrm{~L}(1)$ & 461,1224 & $\mathrm{~L}(1)$ & $\mathrm{L}(1)$ & Benar \\
\hline 2 & $\mathrm{~L}(2)$ & 451,6505 & $\mathrm{~L}(2)$ & $\mathrm{L}(2)$ & Benar \\
\hline 3 & $\mathrm{~L}(3)$ & 500,8706 & $\mathrm{~L}(3)$ & $\mathrm{L}(3)$ & Benar \\
\hline 4 & $\mathrm{~L}(4)$ & 470,0423 & $\mathrm{~L}(4)$ & $\mathrm{L}(4)$ & Benar \\
\hline 5 & $\mathrm{~L}(5)$ & 475,2740 & $\mathrm{~L}(5)$ & $\mathrm{L}(5)$ & Benar \\
\hline 6 & $\mathrm{P}(2)$ & 448,1504 & $\mathrm{P}(2)$ & $\mathrm{P}(2)$ & Benar \\
\hline 7 & $\mathrm{P}(2)$ & 445,8844 & $\mathrm{P}(2)$ & $\mathrm{P}(2)$ & Benar \\
\hline 8 & $\mathrm{P}(3)$ & 409,7215 & $\mathrm{P}(3)$ & $\mathrm{P}(3)$ & Benar \\
\hline 9 & $\mathrm{P}(4)$ & 430,1859 & $\mathrm{P}(4)$ & $\mathrm{P}(4)$ & Benar \\
\hline 10 & $\mathrm{P}(5)$ & 414,5848 & $\mathrm{P}(5)$ & $\mathrm{P}(5)$ & Benar \\
\hline
\end{tabular}

Untuk Mengetahui tingkat akurasi dari pada citra basis data maka dilakukan dengan persamaan sebagai berikut.

Akwrasi basis (96) $=\frac{2 \text { Pengujian }- \text { Kesalahan }}{\sum \text { Pengujian }} \times 10036=\frac{10-0}{10} \times 10036=10036$

C. Proses Pengujian Citra

1. Hasil Pengujian Bernilai Benar, perhatikan pada gambar 19 adalah hasil pengujian yang prosesnya benar.

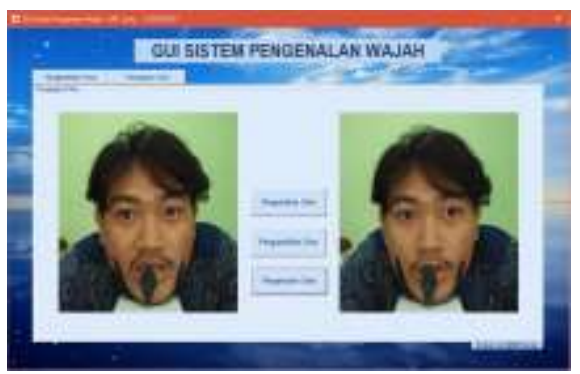

Gambar 19. Hasil Pengujian Benar

2. Hasil Pengujian Bernilai Salah,, perhatikan pada gambar 20 adalah hasil pengujian yang prosesnya benar. 


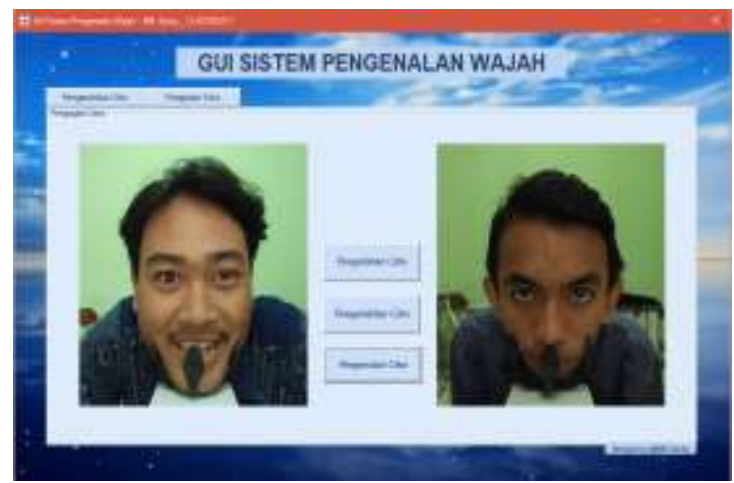

Gambar 20. Hasil Pengujian Salah

3. Hasil pengujian bernilai salah, perhatikan pada gambar 19 adalah hasil pengujian yang prosesnya benar.

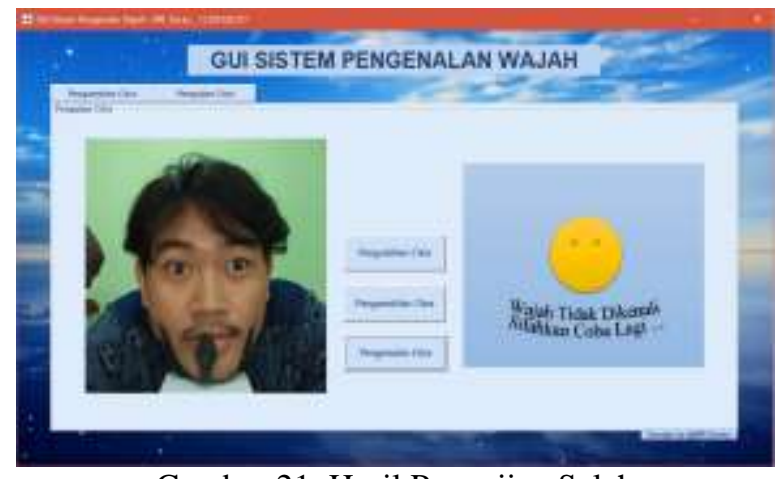

Gambar 21. Hasil Pengujian Salah

4. Hasil Pengujian Sistem Pengenalan Wajah, perhatikan tabel IV dan V, tabel berdasarkan lakilaki dan perempuan.

Tabel IV

Tabel Hasil Pengujian Laki-laki

\begin{tabular}{|c|c|c|c|c|c|}
\hline No & $\begin{array}{c}\text { Data } \\
\text { Citra }\end{array}$ & Nilai PD & Target & Hasil & Keterangan \\
\hline 1 & L(1) & 460,2404 & L (1) & L (1) & Benar \\
\hline 2 & L(1) & 460,2677 & L (1) & L (1) & Benar \\
\hline 3 & L(1) & 459,8765 & L (1) & L (1) & Benar \\
\hline 4 & L(1) & 458,2326 & L (1) & L (1) & Benar \\
\hline 5 & L(1) & 459,3864 & L (1) & L (1) & Benar \\
\hline 6 & L(1) & 457,9766 & L (1) & N/A & Salah \\
\hline 7 & L(1) & 462,1760 & L (1) & L (1) & Benar \\
\hline 8 & L(1) & 460,7670 & L (1) & L (1) & Benar \\
\hline 9 & L(1) & 460,9283 & L (1) & L (1) & Benar \\
\hline 10 & L(1) & 460,8630 & L (1) & L (1) & Benar \\
\hline 11 & L(2) & 453,3203 & L (2) & L (2) & Benar \\
\hline 12 & L(2) & 452,9241 & L (2) & L (2) & Benar \\
\hline 13 & L(2) & 453,4541 & L (2) & L (2) & Benar \\
\hline 14 & L(2) & 452,3379 & L (2) & L (2) & Benar \\
\hline 15 & L(2) & 452,8612 & L (2) & L (2) & Benar \\
\hline 16 & L(2) & 452,9302 & L (2) & L (2) & Benar \\
\hline 17 & L(2) & 451,4959 & L (2) & L (2) & Benar \\
\hline 18 & L(2) & 451,5008 & L (2) & L (2) & Benar \\
\hline 19 & L(2) & 453,2106 & L (2) & L (2) & Benar \\
\hline 20 & L(2) & 452,2147 & L (2) & L (2) & Benar \\
\hline 21 & L(3) & 503,8953 & L (3) & L (3) & Benar \\
\hline 22 & L(3) & 500,9384 & L (3) & L (3) & Benar \\
\hline
\end{tabular}

\begin{tabular}{|c|c|c|c|c|c|}
\hline No & $\begin{array}{c}\text { Data } \\
\text { Citra }\end{array}$ & Nilai PD & Target & Hasil & Keterangan \\
\hline 23 & L(3) & 504,9970 & L (3) & L (3) & Benar \\
\hline 24 & L(3) & 505,4011 & L (3) & L (3) & Benar \\
\hline 25 & L(3) & 504,7332 & L (3) & L (3) & Benar \\
\hline 26 & L(3) & 505,2240 & L (3) & L (3) & Benar \\
\hline 27 & L(3) & 504,4823 & L (3) & L (3) & Benar \\
\hline 28 & L(3) & 503,6733 & L (3) & L (3) & Benar \\
\hline 29 & L(3) & 503,0324 & L (3) & L (3) & Benar \\
\hline 30 & L(3) & 505,9923 & L (3) & N/A & Salah \\
\hline 31 & L(4) & 461,0708 & L (4) & L (1) & Salah \\
\hline 32 & L(4) & 467,5596 & L (4) & L (4) & Benar \\
\hline 33 & L(4) & 466,2823 & L (4) & L (4) & Benar \\
\hline 34 & L(4) & 471,6924 & L (4) & L (5) & Salah \\
\hline 35 & L(4) & 475,3116 & L (4) & L (5) & Salah \\
\hline 36 & L(4) & 464,2413 & L (4) & N/A & Salah \\
\hline 37 & L(4) & 473,8034 & L (4) & L (5) & Salah \\
\hline 38 & L(4) & 466,2376 & L (4) & L (4) & Benar \\
\hline 39 & L(4) & 464,5239 & L (4) & N/A & Salah \\
\hline 40 & L(4) & 473,4734 & L (4) & L (5) & Salah \\
\hline 41 & L(5) & 475,4318 & L (5) & L (5) & Benar \\
\hline 42 & L(5) & 473,1243 & L (5) & L (5) & Benar \\
\hline 43 & L(5) & 476,4913 & L (5) & N/A & Salah \\
\hline 44 & L(5) & 474,1797 & L (5) & L (5) & Benar \\
\hline 45 & L(5) & 471,5248 & L (5) & L (5) & Benar \\
\hline 46 & L(5) & 473,8427 & L (5) & L (5) & Benar \\
\hline 47 & L(5) & 469,9351 & L (5) & L (4) & Salah \\
\hline 48 & L(5) & 471,6564 & L (5) & L (5) & Benar \\
\hline 49 & L(5) & 473,8192 & L (5) & L (5) & Benar \\
\hline 50 & L(5) & 473,6952 & L (5) & L (5) & Benar \\
\hline
\end{tabular}


Table V

Tabel Hasil Pengujian Perempuan

\begin{tabular}{|c|c|c|c|c|c|}
\hline No. & $\begin{array}{l}\text { Data } \\
\text { Citra }\end{array}$ & Nilai PD & Target & Hasil & Keterangan \\
\hline 1 & $\mathrm{P}(1)$ & 423,8036 & $\mathrm{P}(1)$ & N/A & Salah \\
\hline 2 & $\mathrm{P}(1)$ & 420,0733 & $\mathrm{P}(1)$ & $\mathrm{P}(1)$ & Benar \\
\hline 3 & $\mathrm{P}(1)$ & 418,8006 & $\mathrm{P}(1)$ & $\mathrm{P}(1)$ & Benar \\
\hline 4 & $\mathrm{P}(1)$ & 420,7333 & $\mathrm{P}(1)$ & $\mathrm{P}(1)$ & Benar \\
\hline 5 & $\mathrm{P}(1)$ & 421,2070 & $\mathrm{P}(1)$ & $\mathrm{P}(1)$ & Benar \\
\hline 6 & $\mathrm{P}(1)$ & 417,8643 & $\mathrm{P}(1)$ & $\mathrm{P}(5)$ & Salah \\
\hline 7 & $\mathrm{P}(1)$ & 417,0232 & $\mathrm{P}(1)$ & $\mathrm{P}(5)$ & Salah \\
\hline 8 & $\mathrm{P}(1)$ & 420,9465 & $\mathrm{P}(1)$ & $\mathrm{P}(1)$ & Benar \\
\hline 9 & $\mathrm{P}(1)$ & 418,9195 & $\mathrm{P}(1)$ & $\mathrm{P}(1)$ & Benar \\
\hline 10 & $\mathrm{P}(1)$ & 420,9462 & $\mathrm{P}(1)$ & $\mathrm{P}(1)$ & Benar \\
\hline 11 & $\mathrm{P}(2)$ & 451,7164 & $\mathrm{P}(2)$ & $\mathrm{L}(2)$ & Salah \\
\hline 12 & $\mathrm{P}(2)$ & 451,7233 & $\mathrm{P}(2)$ & $\mathrm{L}(2)$ & Salah \\
\hline 13 & $\mathrm{P}(2)$ & 447,5984 & $\mathrm{P}(2)$ & $\mathrm{P}(2)$ & Benar \\
\hline 14 & $\mathrm{P}(2)$ & 450,4920 & $\mathrm{P}(2)$ & $\mathrm{P}(2)$ & Benar \\
\hline 15 & $\mathrm{P}(2)$ & 450,0495 & $\mathrm{P}(2)$ & $\mathrm{P}(2)$ & Benar \\
\hline 16 & $\mathrm{P}(2)$ & 451,4662 & $\mathrm{P}(2)$ & $\mathrm{L}(2)$ & Salah \\
\hline 17 & $\mathrm{P}(2)$ & 452,6390 & $\mathrm{P}(2)$ & $\mathrm{L}(2)$ & Salah \\
\hline 18 & $\mathrm{P}(2)$ & 448,9519 & $\mathrm{P}(2)$ & $\mathrm{P}(2)$ & Benar \\
\hline 19 & $\mathrm{P}(2)$ & 448,1552 & $\mathrm{P}(2)$ & $\mathrm{P}(2)$ & Benar \\
\hline 20 & $\mathrm{P}(2)$ & 444,9873 & $\mathrm{P}(2)$ & N/A & Salah \\
\hline 21 & $\mathrm{P}(3)$ & 409,0690 & $\mathrm{P}(3)$ & $\mathrm{P}(3)$ & Benar \\
\hline 22 & $\mathrm{P}(3)$ & 411,5062 & $\mathrm{P}(3)$ & $\mathrm{P}(3)$ & Benar \\
\hline 23 & $\mathrm{P}(3)$ & 408,8588 & $\mathrm{P}(3)$ & $\mathrm{P}(3)$ & Benar \\
\hline 24 & $\mathrm{P}(3)$ & 411,6259 & $\mathrm{P}(3)$ & $\mathrm{P}(3)$ & Benar \\
\hline 25 & $\mathrm{P}(3)$ & 413,1246 & $\mathrm{P}(3)$ & N/A & Salah \\
\hline 26 & $\mathrm{P}(3)$ & 409,4670 & $\mathrm{P}(3)$ & $\mathrm{P}(3)$ & Benar \\
\hline 27 & $\mathrm{P}(3)$ & 408,6992 & $\mathrm{P}(3)$ & $\mathrm{P}(3)$ & Benar \\
\hline 28 & $\mathrm{P}(3)$ & 405,7237 & $\mathrm{P}(3)$ & N/A & Salah \\
\hline 29 & $\mathrm{P}(3)$ & 405,6460 & $\mathrm{P}(3)$ & N/A & Salah \\
\hline 30 & $\mathrm{P}(3)$ & 405,4259 & $\mathrm{P}(3)$ & N/A & Salah \\
\hline 31 & $\mathrm{P}(4)$ & 433,8794 & $\mathrm{P}(4)$ & $\mathrm{P}(4)$ & Benar \\
\hline 32 & $\mathrm{P}(4)$ & 432,5189 & $\mathrm{P}(4)$ & $\mathrm{P}(4)$ & Benar \\
\hline 33 & $\mathrm{P}(4)$ & 434,1817 & $\mathrm{P}(4)$ & $\mathrm{P}(4)$ & Benar \\
\hline 34 & $\mathrm{P}(4)$ & 433,4522 & $\mathrm{P}(4)$ & $\mathrm{P}(4)$ & Benar \\
\hline 35 & $\mathrm{P}(4)$ & 429,6893 & $\mathrm{P}(4)$ & N/A & Salah \\
\hline 36 & $\mathrm{P}(4)$ & 428,7679 & $\mathrm{P}(4)$ & N/A & Salah \\
\hline 37 & $\mathrm{P}(4)$ & 430,2370 & $\mathrm{P}(4)$ & $\mathrm{P}(4)$ & Benar \\
\hline 38 & $\mathrm{P}(4)$ & 431,9831 & $\mathrm{P}(4)$ & $\mathrm{P}(4)$ & Benar \\
\hline 39 & $\mathrm{P}(4)$ & 432,0929 & $\mathrm{P}(4)$ & $\mathrm{P}(4)$ & Benar \\
\hline 40 & $\mathrm{P}(4)$ & 430,7099 & $\mathrm{P}(4)$ & $\mathrm{P}(4)$ & Benar \\
\hline 41 & $\mathrm{P}(5)$ & 418,7949 & $\mathrm{P}(5)$ & N/A & Salah \\
\hline 42 & $\mathrm{P}(5)$ & 418,8537 & $\mathrm{P}(5)$ & N/A & Salah \\
\hline 43 & $\mathrm{P}(5)$ & 414,0610 & $\mathrm{P}(5)$ & $\mathrm{P}(5)$ & Benar \\
\hline 44 & $\mathrm{P}(5)$ & 416,3511 & $\mathrm{P}(5)$ & $\mathrm{P}(5)$ & Benar \\
\hline 45 & $\mathrm{P}(5)$ & 415,2278 & $\mathrm{P}(5)$ & $\mathrm{P}(5)$ & Benar \\
\hline 46 & $\mathrm{P}(5)$ & 414,4714 & $\mathrm{P}(5)$ & $\mathrm{P}(5)$ & Benar \\
\hline 47 & $\mathrm{P}(5)$ & 414,6947 & $\mathrm{P}(5)$ & $\mathrm{P}(5)$ & Benar \\
\hline 48 & $\mathrm{P}(5)$ & 415,1542 & $\mathrm{P}(5)$ & $\mathrm{P}(5)$ & Benar \\
\hline 49 & $\mathrm{P}(5)$ & 414,0095 & $\mathrm{P}(5)$ & $\mathrm{P}(5)$ & Benar \\
\hline 50 & $\mathrm{P}(5)$ & 415,5658 & $\mathrm{P}(5)$ & $\mathrm{P}(5)$ & Benar \\
\hline
\end{tabular}

Berdasarkan hasil pengujian sistem pengenalan wajah pada tabel IV dan V maka untuk mengetahui nilai tingkat akurasinya sebagai berikut.
Akurasi Sistem (96) $=\frac{2 \text { Pengrijian }- \text { Kascilahan }}{\sum \text { Pengujian }} \times 10036=\frac{100-27}{100} \times 10036=7336$

Dan untuk tingkat akurasi laki-laki berdasarkan tabel IV adalah sebagai berikut.

$$
\text { Akurasi Laki-Laki }(\phi 6)=\frac{50-11}{50} \times 100 \%=78 \%
$$

Dan untuk tingkat akurasi Perempuan berdasarkan tabel 4.5 adalah sebagai berikut.

$$
\text { AkurasiPerempuan }(\%)=\frac{50-16}{50} \times 100 \%=68 \%
$$

\section{KESIMPULAN}

A. Kesimpulan sebagai berikut sebagai berikut:

1) Pengujian sistem pengenalan wajah yang telah dirancang dalam penelitian ini memiliki tingkat akurasi $73 \%$. Akurasi pada laki-laki sebesar $78 \%$ dan $68 \%$ pada perempuan.

2) Metode viola-jones dan Euclidean Distance dapat digunakan dengan baik.

3) GUI MATLAB yang di rancang dapat digunakan dan berjalan dengan baik

4) Kecepatan rata-rata proses pencocokan citra wajah adalah sekitar 2-3 detik.

\section{B. SARAN}

Saran untuk pengembangan kedepannya yakni perlu adanya perbaikan pada alat peragaan dan perancangan perangkat lunak untuk menghasilkan sebuah sistem pengenalan wajah yang lebih baik. Serta perlu adanya kontrol variable yang berpengaruh pada pengambilan citra sepertihalnya pencahayaan.

\section{REFERENSI}

[1] Darma putra, Sistem Biometrika (Konsep Dasar, Teknik Analisa Citra, dan Tahapan Membangun Aplikasi Sistem Biometrika). Yogyakarta: penerbit andi, 2009.

[2] H. . Fatta, Rekayasa Sistem Pengenalan Wajah, 1st ed. Yogyakarta: penerbit andi, 2009.

[3] N. Dodgson, Variation and extrema of human interpupillary distance, vol. 5291. 2004.

[4] R. W. A. Puri, "Pengenalan wajah menggunakan alihragam wavelet haar dan jarak euclidien," J. Tek. Elektro, vol. 0, pp. 1-7, 2010.

[5] M. S. Anam and S. Islam, "Face recognition using genetic algorithm and back propagation neural network," Proc. ..., vol. I, pp. 18-21, 2009.

[6] Ahsanul Intishor, "Pengenalan Wajah dengan Menggunakan Metode Centroid dan Geometric Mean," Universitas Islam Negei Maulana Malik Ibrahim Malang Untuk, 2015.

[7] ILHAM ANDRIAN, "PERBANDINGAN METODE VIOLA JONES dengan METODE ROBERTS CROSS pada sistem PENGENALAN WAJAH," J. Chem. Inf. Model., vol. 53, no. 9, pp. 1689-1699, 2013. 
[8] D. Nugraheny, "Metode Nilai Jarak Guna Kesamaan Atau Kemiripan Ciri Suatu Citra (Kasus Deteksi Awan Cumulonimbus Menggunakan Principal Component Analysis)," Angkasa J. Ilm. Bid. Teknol., vol. 7, no. 2, p. 21, 2017.

[9] F. A. Hermawati, Pengolahan Citra Digital, 1st ed. Yogyakarta: penerbit andi, 2011.

[10] V. S. T d Sutoyo, Edy Mulyanto, Teori Pengolahan Citra Digital, 1st ed. Yogyakarta: Penerbit Andi, 2009.

[11] Sahid, Pengantar Komputasi Numerik dengan MATLAB, 1st ed. Yogyakarta: penerbit andi, 2005.

[12] Y. N. Erick Paulus, cepat mahir GUI Matlab, 1st ed. Yogyakarta: penerbit andi, 2007. 